\title{
Measurement of urinary calcium/creatinine and sodium/potassium excretion in healthy children aged 1-7 years in Imam Ali Hospital, Andimeshk in 2008
}

\author{
Morad Rostami $^{1 *}$, Mohammad Aberomand ${ }^{1}$, Alireza Khirollah ${ }^{1}$ and Masoomeh Jorfi ${ }^{2}$ \\ ${ }^{1}$ Biochemistry Department, Faculty of Medicine, Ahvaz Jundishapur University of Medical Sciences, Iran. \\ ${ }^{2}$ Microbiology Department, Faculty of Medicine, Ahvaz Jundishapur University of Medical Sciences, Iran.
}

Accepted 7 June, 2012

\begin{abstract}
Due to the difficulty in obtaining a $24 \mathrm{~h}$ urine collection in children, a random sample of urine is often used to calculate the urine calcium to creatinine ratio. Also, urinary calcium excretion might be influenced by genetic, geographic area, etc. we decided to evaluate the urinary calcium, creatinine, sodium and potassium excretion in healthy children with 1-7 years and determine age-related reference values for urine calcium to creatinine and sodium to potassium ratio in Andimeshk City in Khozestan Province of Iran. From 1155 healthy children (528 boys and 627 girls) with ages between 1-7 years, that referred to check-up to Imam Ali Hospital in Andimeshk, between January and December 2008, urine sample was collected and calcium, creatinine, sodium and potassium were measured. From 1155 healthy children, $528(45.7 \%)$ were boys and $627(54.3 \%)$ were girls. Mean \pm SD ratio of urine calcium to creatinine in all children was $0.165 \pm 0.115$. This ratio was $0.168 \pm 0.114$ and $0.163 \pm 0.093$ for boys and girls, respectively, but not significant $(p=0.37)$. Also, the mean $\pm S D$ ratio of urine sodium to potassium in all children was $1.981 \pm 1.322$. This ratio was $1.982 \pm 0.912$ and $1.980 \pm 1.108$ for boys and girls, respectively, it was higher in boys than girls, but not significant $(p=0.28)$. Because of warm climate in Khuzestan Province in Iran and relatively, high quantities of solutes in children's urine of this region, suggested that more investigation is done and prevalence of kidney's stone will particularize.
\end{abstract}

Key words: Hypercalciuria, calcium, creatinine, sodium, potassium.

\section{INTRODUCTION}

Idiopathic hypercalciuria has been increasingly recognized as a cause of urinary tract complication in pediatrics (Langman and Moore, 1984). Clinical manifestations of hypercalciuria in children are gross or microscopic hematuria, renal calculi, dysuria, enuresis, osteopenia/rickets, abdominal pain, sterile pyuria, renal colic, urinary frequency/urgency, short stature and polyuria, while most children with idiopathic hypercalciuria are asymptomatic (Langman and Moore,

${ }^{*}$ Corresponding author. E-mail: morad_r56@yahoo.com. Tel: +989163470338.
1984; So et al., 2001). Hypercalciuria is defined as urinary calcium excretion more than $4 \mathrm{mg} / \mathrm{kg} /$ day (Langman and Moore, 1984). Urinary solute to creatinine ratio is a useful and reliable factor for determining hypercalciuria and also is a non-invasive and relative cheap method and other hand, for every age-group, different urine calcium to creatinine ratio was reported (Ginsbery et al., 1993). Also, urinary calcium excretion might be influenced by genetic, geographic area, sun or light exposure, climate, ethnicity, drinking water and nutrition (Honarpisheh et al., 2009).

Due to the difficulty in obtaining a $24 \mathrm{~h}$ urine collection in children, a random sample of urine is often used to calculate the urine calcium to creatinine ratio and this 
Table 1. Urinary Calcium/Creatinine and Sodium/Potassium excretion ratios among 1-7 years old healthy children's in Andimeshk city, Iran.

\begin{tabular}{|c|c|c|c|c|c|c|c|}
\hline \multirow{2}{*}{$\begin{array}{c}\text { Age } \\
\text { groups }\end{array}$} & \multirow{2}{*}{ Sext } & \multirow{2}{*}{$\mathbf{N}$} & \multicolumn{4}{|c|}{ Mean $\pm S^{*}$} & \multirow{2}{*}{ p-value } \\
\hline & & & Calcium/Creatinine & 95th percentile & Sodium/Potassium & 95th percentile & \\
\hline \multirow{2}{*}{$1-2$} & M & 65 & $0.181 \pm 0.110$ & 0.41 & $2.015 \pm 1.020$ & 4.21 & 0.46 \\
\hline & $\mathrm{F}$ & 53 & $0.175 \pm 0.090$ & 0.39 & $1.997 \pm 1.005$ & 3.83 & \\
\hline \multirow{2}{*}{$2-3$} & M & 90 & $0.176 \pm 0.098$ & 0.43 & $2.033 \pm 0.895$ & 5.42 & 0.47 \\
\hline & $\mathrm{F}$ & 103 & $0.173 \pm 0.068$ & 0.41 & $2.010 \pm 1.010$ & 4.65 & \\
\hline \multirow{2}{*}{$3-4$} & $M$ & 98 & $0.172 \pm 0.095$ & 0.39 & $1.885 \pm 1.025$ & 4.13 & 0.35 \\
\hline & $\mathrm{F}$ & 88 & $0.155 \pm 0.082$ & 0.35 & $1.998 \pm 0.980$ & 4.58 & \\
\hline \multirow{2}{*}{$4-5$} & $M$ & 87 & $0.161 \pm 0.085$ & 0.37 & $2.000 \pm 1.022$ & 4.46 & 0.48 \\
\hline & $\mathrm{F}$ & 114 & $0.163 \pm 0.072$ & 0.39 & $1.887 \pm 0.995$ & 4.12 & \\
\hline \multirow{2}{*}{$5-6$} & M & 103 & $0.165 \pm 0.087$ & 0.36 & $2.003 \pm 1.005$ & 5.28 & 0.42 \\
\hline & $\mathrm{F}$ & 117 & $0.158 \pm 0.064$ & 0.31 & $1.978 \pm 0.884$ & 4.73 & \\
\hline \multirow{2}{*}{$6-7$} & M & 121 & $0.150 \pm 0.090$ & 0.32 & $1.955 \pm 0.990$ & 4.37 & 0.10 \\
\hline & $\mathrm{F}$ & 116 & $0.152 \pm 0.096$ & 0.37 & $2.010 \pm 1.032$ & 5.69 & \\
\hline
\end{tabular}

*Standard deviation, †M: Male; F: Female.

ratio is routinely used in clinical practice to screen for hypercalciuria as it is found to have a good correlation with the $24 \mathrm{~h}$ calcium excretion (So et al., 2001). Traditionally, if a urine calcium to creatinine ratio is greater than 0.21, considered abnormal and suggestive of hypercalciuria in children (Pak et al., 1975). Also, some of the researches showed a direct association between urinary sodium/potassium ratio with urinary calcium/creatinine ratio in hypercalciuric patients (Osorio and Alon, 1997) and increased risk of urolithiasis (Cirllo et al., 1996).

Due to our search in internet, no study has been done in children of 1 to 7 years in the world, and also, no study has been done on this subject in Khozestan province up to now. Therefore, we decided to evaluate the urinary calcium, creatinine, sodium and potassium excretion in healthy children with 1 to 7 years and determine age related reference values for urine calcium to creatinine ratio in Andimeshk city in Khozestan province of Iran.

\section{MATERIALS AND METHODS}

This is a descriptive study conducted in Andimeshk city in the north of Khozestan province. Khozestan province is located at the southwestern of Iran with very hot and humid climate in the most months of the year. In this study, from 1155 healthy children (528 boys and 627 girls) with ages between 1 to 7 years, that referred to check-up to Imam Ali hospital in Andimeshk, between January and December 2008, urine sample is collected. All of the children had normal examination and growth and not eating habits, physical activities, any history of kidney or urinary tract diseases. This finding is obtained according to physical examination by hospital's physician and questionnaire that are filled by their parents. The consent form was obtained from all participants. Random urine samples were obtained from each subject, collected in a coded plastic sealed container and sent to biochemistry department of laboratory immediately. Calcium and creatinine of urine samples, were measured by BS-300 Mindry Autoanalyzer and sodium and potassium were measured by Convergys ISE Analyzer (Flameless flame photometer), immediately.

\section{RESULTS}

From 1155 healthy children, 528 (45.7\%) were boys and $627(54.3 \%)$ were girls. The number of each groups are listed in Table 1. Mean \pm SD ratio of urine calcium to creatinine in all children was $0.165 \pm 0.115$. The mean \pm $\mathrm{SD}$ of urine calcium to creatinine ratio for boys and girls was $0.168 \pm 0.114$ and $0.163 \pm 0.093$, respectively. The urine calcium to creatinine ratio is higher in boys than girls, but not significant $(p=0.37)$. Also, the mean \pm SD ratio of urine sodium to potassium in all children was 1.981 \pm 1.322 . The mean \pm SD of urine sodium to potassium ratio for boys and girls was $1.982 \pm 0.912$ and $1.980 \pm 1.108$, respectively. The urine sodium to potassium ratio is higher in boys than girls, but not significant $(p=0.28)$.

\section{Conclusions}

According to our study, the mean $\pm S D$ urinary calcium to creatinine and sodium to potassium ratio in 1 to 7 healthy children in Andimeshk City were $0.165 \pm 0.115$ and 
$1.981 \pm 1.322$, respectively. In our study, the urinary calcium to creatinine and sodium to potassium ratio are higher in boys than girls, but this differences not significant.

In the study of Nikibakhsh et al. (2008), the mean calcium to creatinine ratio in primary school children in Urmia (the city in the north-west of Iran), was 0.11 . In their study, have not find any differences between males and females that compatible with our study. Esbjorner and Jones (1995) reported normal urine calcium to creatinine ratio as high as 0.44 in 2 to 18 years healthy Swedish children. Ceran et al. (2003) reported urine calcium to creatinine ratio equal to 0.1 in Turkish children that lower than our results. Safarinejad (2003) reported extremely low calcium to creatinine ratio as low as 0.04 in an Iranian healthy children population.

Ceran et al. (2003) reported that children under 7 months have 3 fold higher urine calcium to creatinine ratio compared to ones above 7 years. Also, So et al. (2001) reported that urine calcium to creatinine ratio is decreased by aging.

Sargent et al. (1993) suggested that high levels of urine calcium to creatinine ratio in infants may be secondary to low creatinine excretion per unit body mass. Cirllo et al. (1996) showed an association between high urinary sodium to potassium ratio and increased risk of urolithiasis. A direct correlation between urine calcium to creatinine ratio and urine sodium to potassium ratio in hypercalciuric patients has been shown by Osorio and Alon (1997). They suggested that increased potassium intake in hypercalciuric children has beneficial effect on urine calcium to creatinine ratio and patient's symptoms. $S$ factors such as dietary habits, warm climate, etc. are involved in kidney stone formation (Curhan et al., 1997). Because of high quantities of solutes in children's urine of this region and warm climate in Khuzestan province in Iran, the risk of renal stone formation are high and therefore, it is suggested that more investigation in other Khuzestan cities will be done and also, the prevalence of kidney's stone in this children will particularize.

\section{ACKNOWLEDGEMENT}

This study was supported by Ahvaz Jundishapur University of Medical Sciences, grant No. 88.S.51. We thank Imam Ali laboratory personals for their expert laboratory assistance.

\section{REFERENCES}

Ceran O, Akin M, Akturk Z et al., (Provide Complete Name) (2003). Normal calcium/creatinine ratios in Turkish children. Indian Pediatr. 40(9):884-887.

Cirllo M, Laurenzi M, Panarelli W et al., (Provide Complete Name) (1996). Urinary sodium to potassium ratio and urinary stone disease. Kidney Int. 46(4):1133-1139.

Curhan GC, Willett WC, Rimm EB et al., (Provide Complete Name) (1997). Family history and risk of kidney stones. J. Am. Soc. Nephrol. 8:1568-1573.

Esbjorner E, Jones IL (1995). Urinary calcium excretion in Swedish children. Acta Pediatr. 84(2):156-159.

Ginsbery JM, Chang BS, Matarese RA et al., (Provide Complete Name) (1993). Use of single voided urine samples to estimate proteinuria. Engl. J. Med. 309:1543-1546.

Honarpisheh A, Hooman N, Taghavi A (2009). Urinary calcium excretion in healthy children living in Kashan/Iran. Iran J. Pediatr. 19:154-158

Langman CB, Moore ES (1984). Hypercalciuria in clinical pediatrics. Clin. Pediatr. 23(3):135-137.

Nikibakhsh A, Seyedzadeh A, Mahmoodzadeh H et al., (Provide Complete Name) (2008). Normal values for random urinary calcium to creatinine ratio in Iranian children. Iran J. Pediatr. 18:263-266.

Osorio AV, Alon US (1997). The relationship between urinary calcium, sodium and potassium excretion and the role of potassium in treating idiopathic hypercalciuria. Pediatrics 100(4):675-681.

Pak CY, Kaplan R, Bone H et al., (Provide Complete Name) (1975). A simple test for the diagnosis of absorptive and renal hypercalciurias. N. Engl. J. Med. 292:497-500.

Safarinejad MR (2003). Urinary mineral excretion in healthy Iranian children. Pediatr. Nephrol. 18(2):140-144.

Sargent JD, Stukel TA, Kresel J (1993). Normal values random urinary calcium to creatinine ratios in infancy. J. Pediatr. 123:393-397.

So NP, Osorio AV, Simon SD, Alan US (2001). Normal Urinary calcium/creatinine ratio in African-American and Caucasian children. Pediatr. Nephrol. 16(2):133-139. 